\title{
Is Lead Dust Within Nuclear Medicine Departments a Hazard to Pediatric Patients?
}

\author{
Shannon M. Hulbert and Katherine A. Carlson \\ Nuclear Medicine Technology Program, Indiana University School of Medicine, Indianapolis, Indiana
}

Because of the penetrating ability of the radiation used in nuclear medicine, metallic lead is widely used as radiation shielding. However, this shielding may present an insidious health hazard because of the dust that is readily removed from the surfaces of lead objects. The lead dust may become airborne, contaminate floors and other nearby surfaces, and be inadvertently inhaled or ingested by patients. We determined if the quantity of lead dust encountered within nuclear medicine departments exceeded Environmental Protection Agency (EPA) standards. Methods: For lead dust quantification, professional lead test kits were used to sample fifteen $1-\mathrm{ft}^{2}$ sections of different surfaces within the department. Four samples were collected once per week from each site. The samples were then submitted to a National Lead Laboratory-accredited program for a total lead measurement. Lead contamination $\left(\mu \mathrm{g} / \mathrm{ft}^{2}\right)$ for each of the 60 samples was compared with the EPA standards for lead dust. Results: Lead contamination was present at 6 of the 15 sites, and of 60 samples, 18 exceeded the EPA standard of 50 $\mu \mathrm{g} / \mathrm{ft}^{2}$. Conclusion: Lead contamination is present within nuclear medicine departments, and corrective measures should be considered when dealing with pediatric patients. A larger series needs to be conducted to confirm these findings.

Key Words: radiation shielding; lead dust hazards; lead contamination

J Nucl Med Technol 2009; 37:170-172

DOI: 10.2967/jnmt.109.062281

\section{B} ecause of the penetrating ability of the radiation used in nuclear medicine, shielding is necessary. Lead and some of its alloys are generally the most cost-effective shielding materials to protect against the effects of $\gamma$ - and x-rays. The properties of lead that make it an excellent shielding material are its density, high atomic number, level of stability, ease of fabrication, high degree of flexibility in application, and availability (1). The most common shielding objects used in nuclear medicine are lead bricks and lead shields for syringes containing radioactive materials. Lead bricks are usually found within the radio-

Received Feb. 14, 2009; revision accepted Apr. 28, 2009.

For correspondence or reprints contact: Shannon M. Hulbert, 541 Clinical Dr., Room 120, Indianapolis, IN 46202-5111.

E-mail: shulbert@iupui.edu

COPYRIGHT $\odot 2009$ by the Society of Nuclear Medicine, Inc. pharmacy and are used to shield against higher radiation levels. However, other lead shields that contain the patient's dose can be found within patient areas. Unfortunately, lead may present an insidious health hazard to pediatric patients because of the lead dust that is readily removed from the surface of lead objects. Although the density of lead dust is high, it may still become airborne, contaminate floors and other nearby work surfaces, and be inadvertently inhaled or ingested (2). Lead dust liberated within the imaging areas may be available to the exploring fingers of pediatric patients.

Lead dust is a major source of lead exposure in children. Lead dust is taken in through the lungs and gastrointestinal tract. Because children have a higher respiratory rate than adults do, children tend to respire and absorb more airborne lead. After absorption, lead enters the child's bloodstream, where it becomes a powerful and versatile toxin. Lead can affect the central and peripheral nervous systems, bone marrow, kidneys, myocardium, and the endocrine and immune systems. The only way to eliminate pediatric lead toxicity is to identify the source of lead contamination and terminate exposure to the source before it enters the child's system (3).

The purpose of this study was to determine whether the quantity of lead dust encountered within nuclear medicine departments presents a health hazard to pediatric patients.

\section{MATERIALS AND METHODS}

We identified 15 areas within the nuclear medicine department of a children's hospital (Fig. 1) that varied in location and type of surface. These areas were outlined into 1 by $1 \mathrm{ft}(1 \mathrm{ft}=0.3048 \mathrm{~m})$ sections with masking tape. HomeSafe Environmental Inc. supplied the materials needed for the lead test kits that were used to obtain the lead dust samples. Guidance on obtaining the samples was also provided and was based on the current industry standard practices and reflected procedures used by certified lead inspectors and risk assessors.

Once the dust wipes had been opened and the caps of the test tubes removed, disposable gloves were put on. The dust wipe was placed and secured on the palm of the hand with the thumb and little finger. Designated areas to be sampled were wiped from side to side using an S-shaped motion, without touching any region outside the selected area. The dust wipe was then folded in half, placing the dirty sides together. Again, the same area was wiped but this time from top to bottom using the same S-shaped motion. 


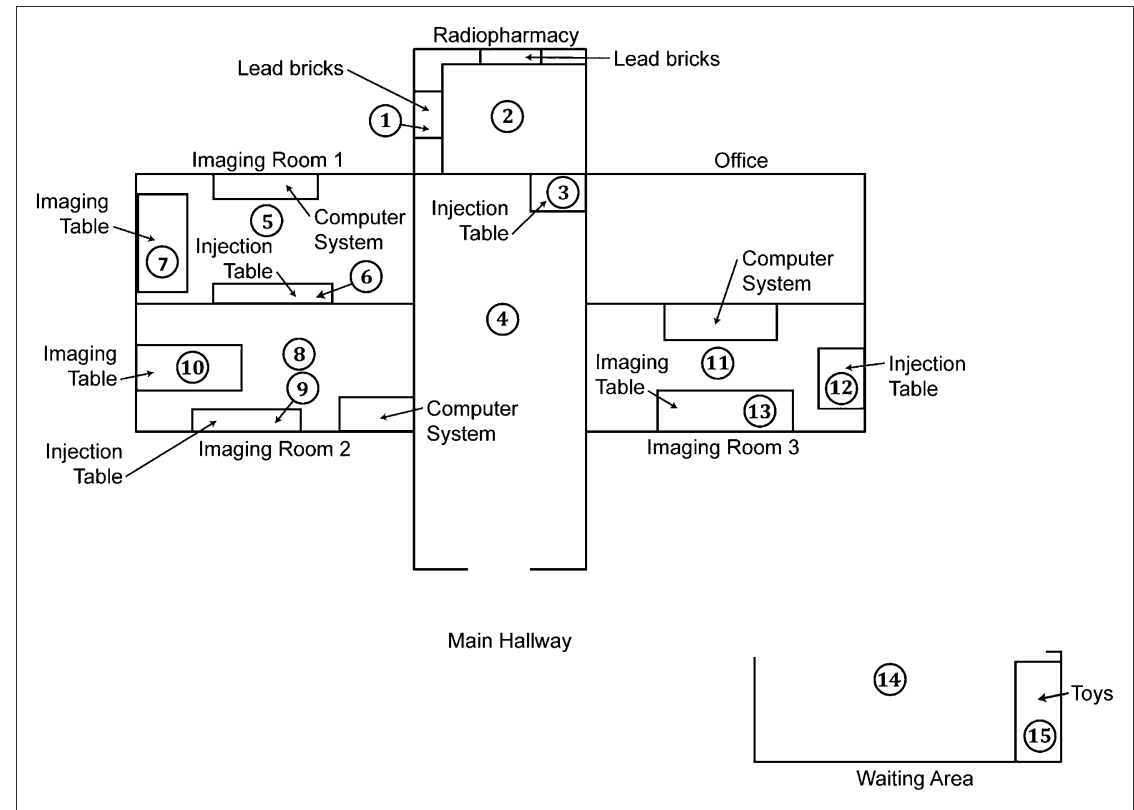

FIGURE 1. Outline of nuclear medicine department of pediatric hospital and areas where wipe samples were obtained.
Once again, the dirty sides of the wipe were folded together; the wipe was now roughly a quarter of the original size and was used a third and final time to wipe the area from side to side. The wipe was placed into the properly labeled test tube and the cap was sealed. The disposable gloves were removed and placed into a plastic trash bag. Within the taped sample area, measurements were taken and recorded to the nearest eighth of an inch (to confirm a 1 by $1 \mathrm{ft}$ section). All 15 areas were individually wiped using this method. The procedure was repeated weekly for 3 additional weeks using the same method, number of wipes, and locations within the department. Thus, 60 samples were obtained
(4 from each site). To evaluate the removal of lead dust from radiation-shielding surfaces, wipe samples were also obtained from the lead bricks. The lead bricks were not cleaned or manipulated in any way before the wipe samples were collected.

The lead dust wipes were sent to the Environmental Hazard Services Laboratory in Richmond, Virginia, for a complete lead analysis. The results were recorded in $\mu \mathrm{g} / \mathrm{ft}^{2}$. Lead contamination for each of the 60 samples was calculated and compared with the Environmental Protection Agency (EPA) lead dust standard (50 $\left.\mu \mathrm{g} / \mathrm{ft}^{2}\right)$. Anything over the EPA standard was considered significant.

TABLE 1

Lead Wipe Samples Obtained Within Nuclear Medicine Department

\begin{tabular}{|c|c|c|c|c|c|c|}
\hline \multirow[b]{2}{*}{ Sample no. } & \multicolumn{4}{|c|}{ Contaminations $\left(\mu \mathrm{g} / \mathrm{ft}^{2}\right)$ for week. . } & \multirow{2}{*}{$\begin{array}{l}\text { Mean contaminations } \\
\left(\mu \mathrm{g} / \mathrm{ft}^{2}\right)\end{array}$} & \multirow{2}{*}{$\begin{array}{l}\text { Numbers exceeding } \\
\text { EPA standard }{ }^{\star}\end{array}$} \\
\hline & 1 & 2 & 3 & 4 & & \\
\hline 1 & 6,100 & 3,500 & 5,100 & 5,400 & 5,025 & 4 \\
\hline 2 & 2,300 & 1,300 & 270 & 750 & 1,155 & 4 \\
\hline 3 & 11 & 11 & 11 & 11 & 11 & 0 \\
\hline 4 & 10 & 440 & 25 & 10 & 121.25 & 1 \\
\hline 5 & 9.6 & 9.6 & 9.6 & 9.6 & 9.6 & 0 \\
\hline 6 & 12 & 48 & 12 & 12 & 21 & 0 \\
\hline 7 & 2,200 & 390 & 230 & 210 & 757.5 & 4 \\
\hline 8 & 21 & 12 & 24 & 12 & 17.25 & 0 \\
\hline 9 & 12 & 12 & 11 & 11 & 11.5 & 0 \\
\hline 10 & 15 & 22 & 10 & 10 & 14.25 & 0 \\
\hline 11 & 11 & 11 & 11 & 12 & 11.25 & 0 \\
\hline 12 & 9.2 & 9.2 & 9.2 & 9.2 & 9.2 & 0 \\
\hline 13 & 1,100 & 280 & 320 & 460 & 540 & 4 \\
\hline 14 & 10 & 10 & 10 & 10 & 10 & 0 \\
\hline 15 & 88 & 12 & 12 & 12 & 31 & 1 \\
\hline
\end{tabular}




\section{RESULTS}

The results are shown in Table 1. Lead contamination was present at 6 of the 15 sites sampled, and of the 60 samples taken, 18 exceeded the EPA standard of $50 \mu \mathrm{g} / \mathrm{ft}^{2}$. The samples from location 1 were obtained directly from the lead bricks. These numbers, all of which exceeded the EPA standard, show the amount of lead dust that is readily removed from the surfaces of the lead bricks. Samples obtained from locations 2, 7, and 13 were also much higher than the EPA standard. These areas all contained lead bricks near the sampled area.

\section{DISCUSSION}

The U.S. EPA has established maximum allowable levels for lead contamination, which most states adopt as enforceable standards. Among these standards, lead dust is considered a hazard when equal to or exceeding $50 \mu \mathrm{g} / \mathrm{ft}^{2}$ on uncarpeted floors (4). The results of this study confirm that dangerous levels of lead contamination may be present within nuclear medicine departments. Given that lead is an important shielding material for $\gamma$ - and $\mathrm{x}$-rays, it is generally not feasible to eliminate or substitute it. Therefore, other means must be used to minimize health hazards from dispersible lead (2). Most lead contamination found within the patient areas was around areas that contained lead shielding. This finding suggests that different measures within the department should be taken to minimize the amount of contamination. After injecting a pediatric patient, nuclear medicine technologists use lead shielding as an immobilization device during the imaging. This reduces the amount of patient motion and allows the needle to remain in place so another injection will not be needed later within the study. Although this is a great way to use resources within the department, other methods, such as a sandbag, might be acceptable. Another alternative would be encasing the lead shielding with a material such as vinyl, plastisol, polyurethane, or epoxy, which would decrease the amount of lead contamination. Previous studies have shown that a single coat of polyurethane drastically reduces the amount of lead contamination from the surfaces of radiation shielding (2), yet some manufacturers of radiation shielding available for medical use do not encapsulate their shielding equipment (5). Researchers have also concluded that frequent floor and surface cleanings would help prevent lead levels from exceeding EPA limits (2).

\section{CONCLUSION}

At this pediatric clinical site, lead contamination exceeded EPA standards in some areas. By recreating this experiment, nuclear medicine technologists can determine whether the lead contamination within their department is at a level that would be considered hazardous to their pediatric patients.

\section{ACKNOWLEDGMENTS}

We acknowledge the Environmental Hazard Services Laboratory in Richmond, Virginia, for its generous contribution toward this research project, and Doug Patton for all his guidance and support.

\section{REFERENCES}

1. Radiation shielding products specifications. Mayco Industries, Inc., Web site. Available at: http://www.maycoindustries.com/radiation_shielding.htm. Accessed June 18, 2009.

2. Klein RC, Weilandics C. Potential health hazards from lead shielding. Am Ind Hyg Assoc J. 1996;57:1124-1126.

3. Needleman HL. Lead poisoning. In: McMillan JA, Feigin RD, DeAngelis C, Jones MD, eds. Oski's Pediatrics. Philadelphia, PA: Lippincott Williams \& Wilkins; 2006:767-773.

4. Lead; Identification of Dangerous Levels of Lead. 40 CFR 745. United States Environmental Protection Agency Web site. Available at: http://epa.gov/EPATOX/1998/June/Day-03/t14736.htm. Accessed June 18, 2009.

5. L-Block shields. Supertech Web site. Available at: http://www.supertechxray.com/a4800-r.htm. Accessed June 18, 2009. 